\title{
Compostagem como Alternativa de Destinação para o Lodo Flotado de Abatedouro de Frangos
}

\author{
Composting as an Alternative Allocation for Sludge Float Slaughterhouse of Chicken \\ Cristiane Graepin', Andrise Janaína Follmann², Joseane Kölzer Schroeder³, Francieli Neuhaus', \\ Alexandre Couto Rodrigues 5 , Pedro Daniel da Cunha Kemerich ${ }^{6}$ \\ 'Mestranda da Pós-graduação em Engenharia Ambiental da UFSM-RS-Brasil \\ ${ }^{2,3,4}$ Engenheira Ambiental e Sanitarista pela UFSM-RS-Brasil \\ ${ }^{5}$ Professor Adjunto da UFSM/FW-RS-Brasil \\ ${ }^{6}$ Professor Adjunto da UNIPAMPA-RS-Brasil
}

\section{Resumo}

\begin{abstract}
Qualquer atividade humana leva à produção de resíduos, no entanto a sociedade exige continuamente a manutenção e melhoria das condições ambientais, onde diversas técnicas de reaproveitamento ou transformação de resíduos podem ser utilizadas. Uma das técnicas que vem sendo amplamente empregada é a compostagem, onde ocorre a degradação biológica, aeróbica ou anaeróbica de resíduos orgânicos, de modo a produzir uma substância húmica para condicionar o solo. Os abatedouros de frangos constituem-se de grandes fontes geradores de poluição principalmente das águas. Dessa forma o presente trabalho relata a aplicação da compostagem como forma de disposição do lodo gerado no tratamento de efluentes de um abatedouro de frangos. Foram aplicados três tratamentos diferenciados e avaliou-se alguns parâmetros como temperatura, odor, moscas, formigas, larvas na leira, chorume e larvas no chorume e umidade, $\mathrm{pH}$, Nitrogênio, Fósforo, Carbono e potássio. Os resultados apresentaram-se satisfatórios, havendo para cada parâmetro suas particularidades em aspectos positivos e negativos.
\end{abstract}

Palavras-chave: resíduos, matéria orgânica, abatedouro de frangos, destinação ambientalmente correta.

\begin{abstract}
Any human activity leads to the production of waste, however society requires continuous maintenance and improvement of environmental conditions, where various techniques of recycling or waste processing can be used. One technique that has been widely employed is composting, where biological degradation, aerobic or anaerobic organic waste in order to produce a humic substance to condition the soil occurs. The chicken slaughterhouses constitute major sources of pollution generators mainly of water. Thus this paper describes the application of composting as a means of disposal of sludge generated in wastewater treatment of a poultry slaughterhouse. Three different treatments were applied and evaluated some parameters such as temperature, odor, flies, ants, larvae in the windrow, and larvae in manure and manure moisture, $\mathrm{pH}$, nitrogen, phosphorus, carbon and potassium. The results were satisfactory, with its particularities for each parameter in the positive and negative aspects.
\end{abstract}

Keywords: waste, organic matter, chicken abattoir, environmentally correct disposal. 


\section{INTRODUÇÃO}

Toda e qualquer atividade humana leva à produção de resíduos, sendo que a crescente demanda da sociedade pela manutenção e melhoria das condições ambientais tem exigido, das autoridades e das empresas públicas e privadas, atividades capazes de compatibilizar o desenvolvimento às limitações da exploração dos recursos naturais.

Segundo a Política Nacional dos Resíduos Sólidos (BRASIL, 2010) os resíduos podem ter uma disposição final ambientalmente adequada, em aterros, ou para uma destinação final ambientalmente adequada. Como exemplo de destinação final ambientalmente adequada tem-se a reciclagem, a compostagem, a recuperação e o aproveitamento energético, de modo a evitar danos ou riscos à saúde e minimizar os impactos ambientais adversos.

A Portaria $\mathrm{n}^{\circ}$ 15/96 do Ministério do Ambiente define compostagem como sendo um processo de reciclagem onde se dá a degradação biológica, aeróbica ou anaeróbica, de resíduos orgânicos, de modo a proceder à sua estabilização, produzindo uma substância húmica, utilizável em algumas circunstâncias como um condicionador do solo (BRASIL, 1996).

Em condições ideais, a compostagem se desenvolve em três fases distintas: mesofílica, termofílica e resfriamento ou maturação. $\mathrm{Na}$ fase mesofílica predominam temperaturas moderadas até cerca de $40^{\circ} \mathrm{C}$, tendo duração média de dois a cinco dias. Na fase termofílica predominam as altas temperaturas podendo ter duração de poucos dias a várias semanas, de acordo com as características do material a ser compostado. Já a fase de resfriamento e maturação, possui duração de semanas a meses, onde a temperatura se assemelha à do ambiente e ocorre a humificação da matéria orgânica decomposta (RODRIGUES et al., 2006).

Para que o processo de compostagem se desenvolva de maneira satisfatória, é necessário que alguns parâmetros fisico-químicos sejam respeitados permitindo que os microrganismos encontrem condições favoráveis para se desenvolverem e transformarem a matéria orgânica (FERNANDES et al., 1996). Os parâmetros físico-químicos que devem ser monitorados são: temperatura, umidade, aeração, relação $\mathrm{C} / \mathrm{N}, \mathrm{pH}$ e estrutura do material.

Diante disso, os abatedouros de aves podem ser considerados grandes poluidores ambientais, vindo a poluir o solo e as águas. Os efluentes gerados possuem altas concentrações de matéria orgânica solúvel ou em suspensão, resultantes do processamento industrial e da lavagem dos equipamentos e instalações. O aumento da produção influencia diretamente a quantidade de resíduos gerados no processo de industrialização e conseqüentemente ocorre um aumento de fontes potencialmente poluidoras (MORAES; JUNIOR, 2006).

O lodo é um resíduo rico em nitrogênio, apresentando relação $C / N$ entre 5,0 e 11,0. Ele necessita, portanto de um resíduo complementar rico em carbono e pobre em nitrogênio, para que a mistura, criteriosamente determinada, apresente relação C/ $\mathrm{N}$ em torno de 20 ou 30 (FERNANDES, et al, 1996).

Dessa forma, a técnica da compostagem tem por finalidade obter em menor tempo possível, um material estável, rico em húmus e nutrientes minerais, com atributos físicos, químicos e biológicos superiores - sob o aspecto agronômico - àqueles encontrados na matéria-prima (EMATER, 2010).

Objetivou-se empregar a compostagem como alternativa de tratamento para o lodo flotado gerado no tratamento dos efluentes de um abatedouro de frangos.

\section{METODOLOGIA}

O estudo desenvolveu-se em uma empresa na cidade de Frederico Westphalen às margens da BR 386 km 35, Bairro Bela Vista.

Inicialmente houve a preparação da área experimental através do nivelamento do terreno e posteriormente isolamento com a utilização de cercas para evitar a invasão de animais. Para a impermeabilização do solo foram colocadas lonas plásticas, devidamente dimensionadas.

Foram confeccionadas nove leiras em formato piramidal, com altura aproximada de $50 \mathrm{~cm}$, o experimento possuiu três tratamentos, sendo cada tratamento composto por três repetições.

O tratamento $1\left(\mathrm{~T}_{1}\right)$ foi composto por camadas intercaladas de lodo flotado, serragem e composto bacteriano, com seu volume sendo diminuído a cada camada, até obtenção da altura desejada. No tratamento $2\left(\mathrm{~T}_{2}\right)$ as camadas foram confeccionadas com serragem, lodo flotado, calcário 
e palha de milho. Já o tratamento $3\left(\mathrm{~T}_{3}\right)$ foi utilizado como testemunha, sendo as camadas foram confeccionadas com serragem e lodo.

Durante o período em que se processava a compostagem, analisaram-se os parâmetros odor, moscas, formigas, larvas na leira, chorume e larvas no chorume e umidade quanto aos critérios: presença, ausência ou presença intensa.

Após a finalização do processo outros parâmetros como a temperatura, relação C/N (carbono/ nitrogênio), nutrientes (potássio, nitrogênio, fósforo), $\mathrm{pH}$, granulometria e o fator tempo também foram analisados.

Os parâmetros temperatura, umidade, presença de moscas, larvas, chorume e odor foram avaliados semanalmente. A temperatura foi monitorada com o auxílio de um termômetro de álcool conforme as seguintes profundidades e alturas:

- Ponto 1: altura de $15 \mathrm{~cm}$ e profundidade de $20 \mathrm{~cm}$;

- Ponto 2: altura de $15 \mathrm{~cm}$ e profundidade de $50 \mathrm{~cm}$;

- Ponto 3: altura de $30 \mathrm{~cm}$ e profundidade de $20 \mathrm{~cm}$;

- Ponto 4: altura de $45 \mathrm{~cm}$ e profundidade de $20 \mathrm{~cm}$.

\section{RESULTADOS E DISCUSSÃO}

O composto apresentou-se pronto após transcorridas 11 semanas desde o início do experimento. Durante todo este período monitorou-se a temperatura ambiente (Figura 1), pois a mesma serviu para verificar a influência das mesmas sobre a temperatura das leiras.

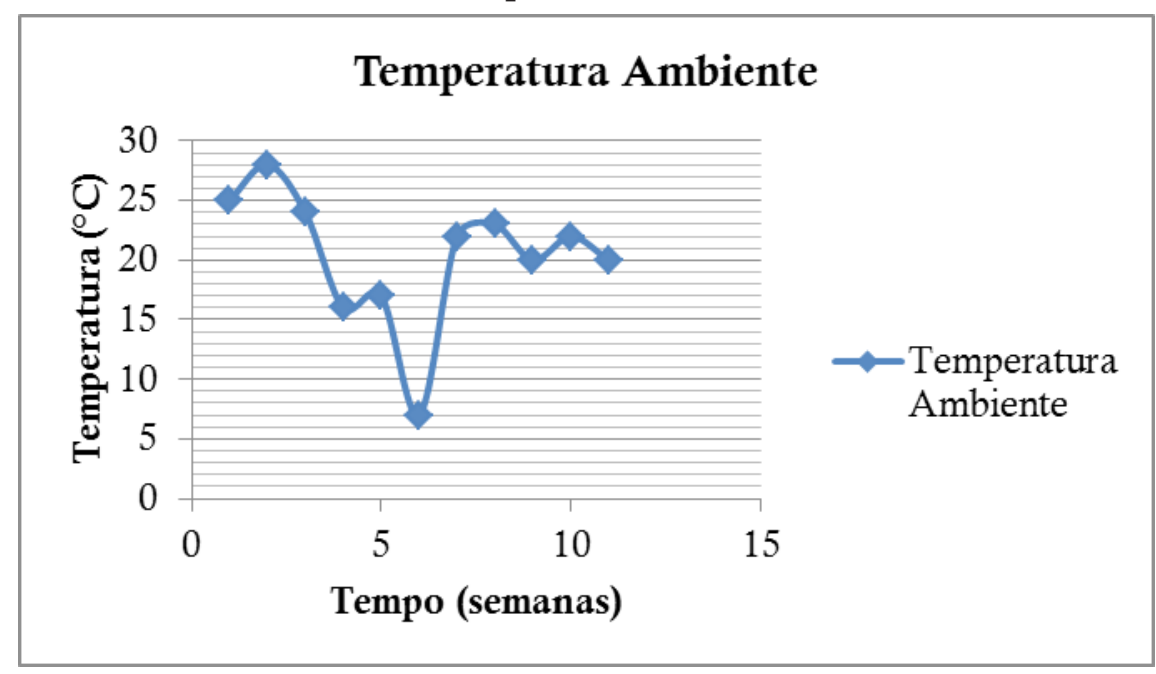

Figura 01 - Gráfico da Temperatura Ambiente

A medição das temperaturas nas leiras teve início após a primeira semana de instalação do experimento, conforme observado nas Figuras 2, 3 e 4.

Como pode-se visualizar, em cada tratamento as temperaturas foram agrupadas, sendo que cada ponto no gráfico indica a média das três repetições de cada tratamento e seus respectivos pontos de medição, totalizando 12 temperaturas, assim como a temperatura máxima e a mínima, para cada dia de avaliação.

A partir dos dados dos gráficos das temperaturas, pode-se observar que o processo de degradação iniciou-se rapidamente, não ocorrendo a primeira fase mesofílica, pois na primeira medição já ocorreram os valores mais elevados de temperatura, caracterizando a fase termofílica.

A segunda fase mesofílica teve duração de aproximadamente três semanas em todos os tratamentos, onde segundo Budziac et al. (2004) nesta fase atuam fungos, bactérias e actinomicetos.

A partir da terceira semana ocorreu uma queda brusca da temperatura nas leiras, juntamente com a temperatura ambiente (Figura 1), caracterizando a fase de resfriamento ou maturação. Até o final do processo houve poucas variações de temperatura, variando conforme a temperatura ambiente. 


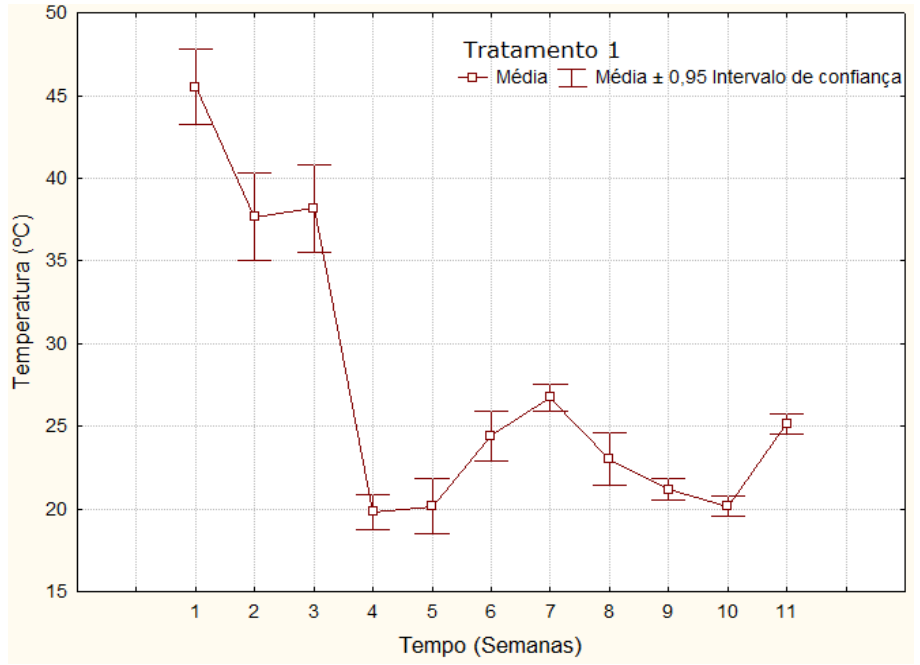

Figura 02 - Gráfico da temperatura do T1 em relação ao tempo (semanas).

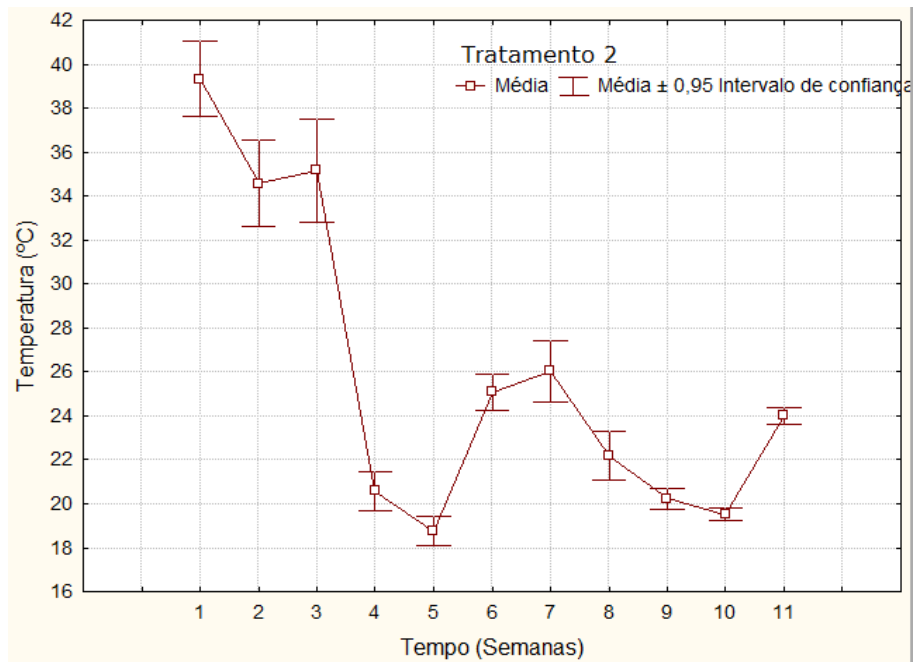

Figura 03 - Gráfico da temperatura do T2 em relação ao tempo (semanas).

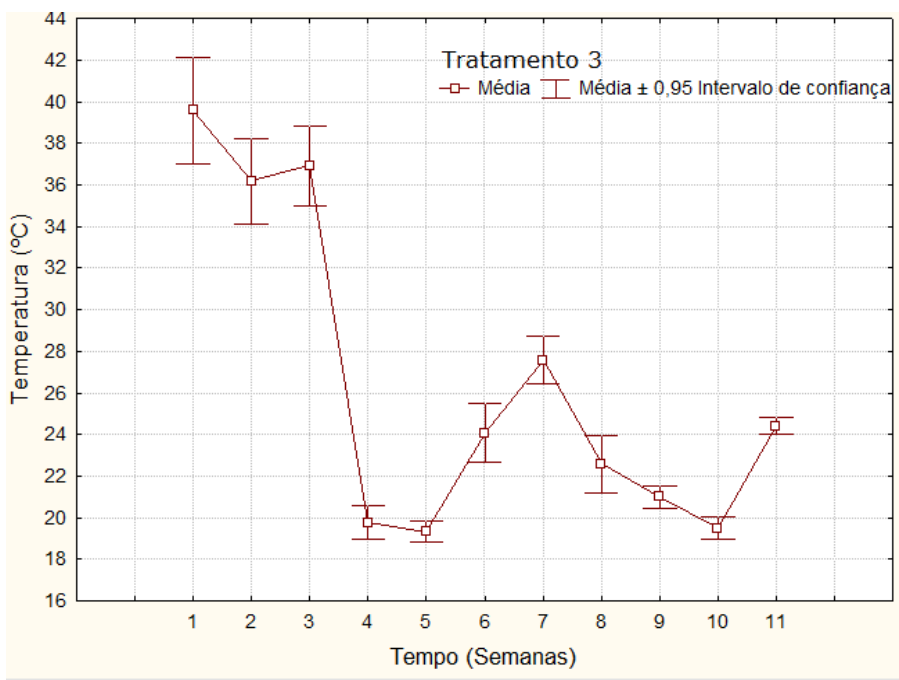

Figura 04 - Gráfico da temperatura do T3 em relação ao tempo (semanas). 
As Figuras 5, 6 e 7 apresentam os parâmetros analisados para cada tratamento, sendo que foram atribuídos valores (notas) de 0 a 2 para quantifica-los, sendo que 0 indicou a ausência do parâmetro, 1 a presença e 2 a presença intensa.

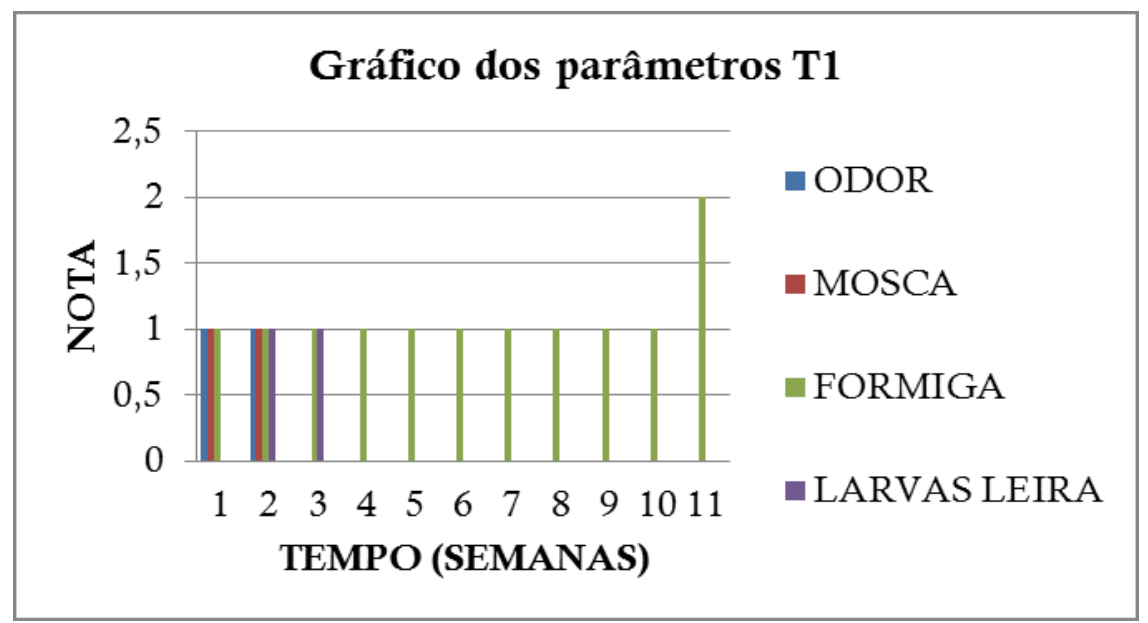

Figura 05 - Parâmetros analisados para o $T_{1}$.

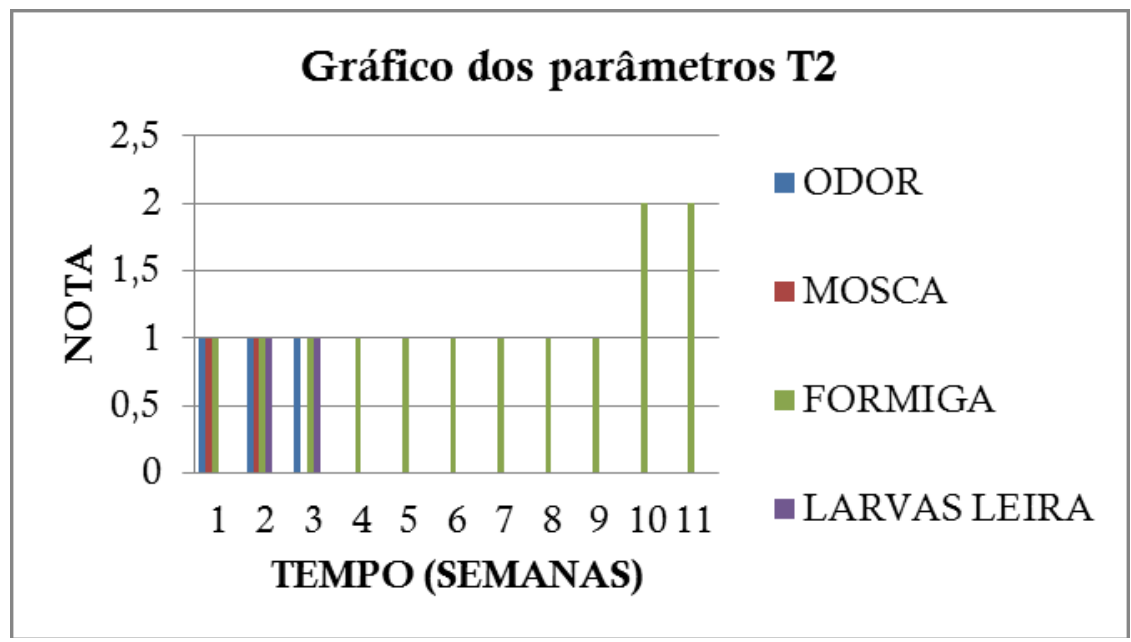

Figura 06 - Parâmetros analisados para o $\mathrm{T}_{2}$.

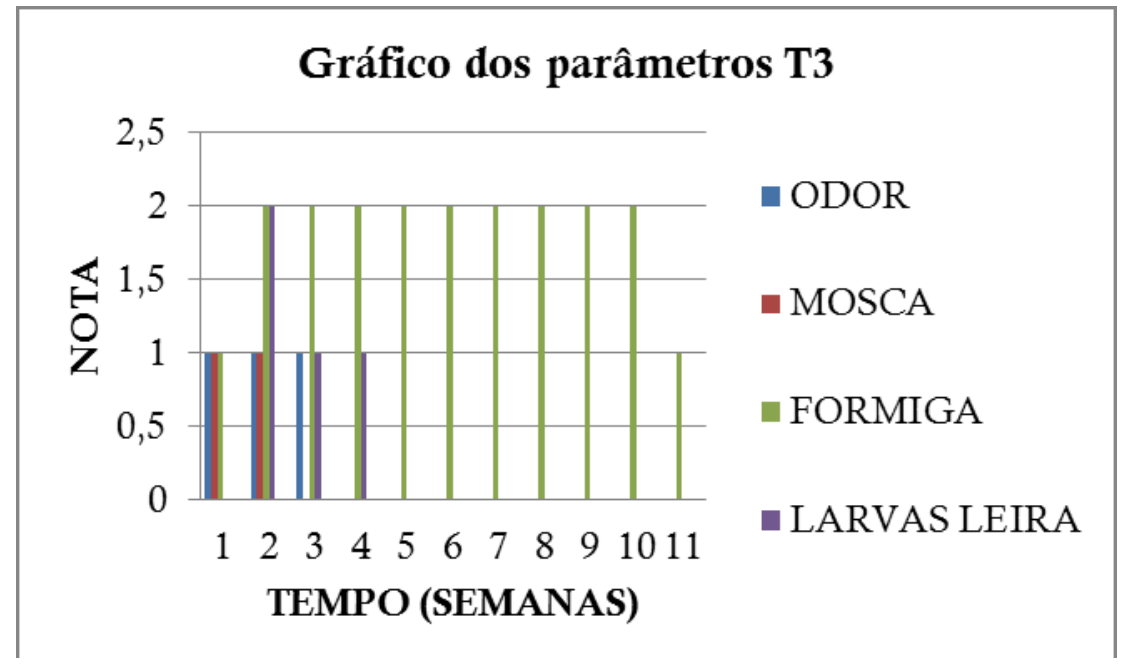

Figura 07 - Parâmetros analisados para o $\mathrm{T}_{3}$. 
A partir dos dados encontrados, observa-se que no início do processo de compostagem todos os tratamentos obtiveram a presença de odor e consequentemente moscas, porém após a quarta semana elas desapareceram, devido à degradação e estabilização da matéria orgânica.

Já a presença de formigas manteve-se constante em todos os tratamentos, esse fato ocorreu devido ao processo estar em andamento, visto que as formigas assim como fungos, bactérias, minhocas, besouros e aranhas fazem parte das etapas da compostagem, acelerando o processo de degradação da matéria orgânica (CARMO, 2008).

Em nenhum dos tratamentos notou-se a presença de chorume e consequente larvas sobre o chorume, devido principalmente as características do material ser compostado (lodo).

A Tabela 1 apresenta os valores obtidos das análises realizadas com o composto pronto.

Tabela 1: Análise complementar dos tratamentos $\mathrm{T}_{1}, \mathrm{~T}_{2}$ e $\mathrm{T}_{3}$.

\begin{tabular}{ccccccc}
\hline Tratamento & Nitrogênio $(\mathbf{g} / \mathbf{k g})$ & Carbono $(\mathbf{g} / \mathbf{k g})$ & $\mathbf{p H}$ & Fósforo (mg/L) & Potássio (mg/L) \\
\cline { 5 - 6 } $\mathrm{T}_{1}$ & 14,59 & 563,1 & 6,65 & 76 & 194,66 \\
$\mathrm{~T}_{2}$ & 8,68 & 284,31 & 7,7 & 239,9 & 158,66 \\
$\mathrm{~T}_{3}$ & 13,2 & 386,79 & 6,95 & 76 & 152 \\
\hline
\end{tabular}

Segundo pesquisa da EMBRAPA (2002) realizada com diferentes adubos orgânicos, dentre eles o composto de lixo orgânico, cama de frango de corte e esterco curtido de bovino, apresentaram valores de Nitrogênio $(\mathrm{g} / \mathrm{kg}$ ) de 30,97 para o composto de lixo orgânico, 20,57 para a cama de frango de corte e 20,10 de esterco curtido de bovino.

Os resultados obtidos de nitrogênio para o lodo de abatedouro foi de $14,59 \mathrm{~g} / \mathrm{kg}$ para o tratamento com bactéria, 13,2 para a testemunha e 8,68 para o tratamento de cálcario, sendo inferior ao composto de lixo orgânico apresentado pela EMBRAPA (2002). Este parâmetro apresentou-se baixo devido a composição das leiras, sendo a maior porcentagem gravimétrica de material presente ser rico em Carbono, apresentando um valor de 563,1 para o tratamento de bactéria, 386,79 para a testemunha e 284,31 para o tratamento com calcário, sendo valores elevados em comparação ao Nitrogênio.

$\mathrm{O} \mathrm{pH}$ do composto aumenta a medida que o processo se desenvolve, atingindo muitas vezes, níveis superiores a 8,0 (KIEHL, 2004). A faixa de $\mathrm{pH}$ considerada ótima para o desenvolvimento dos microrganismos responsáveis pela compostagem situa-se entre 5,5 e 8,5, uma vez que a maioria das enzimas encontram-se ativas nesta faixa de $\mathrm{pH}$ (Rodrigues et al., 2006). Porém, Pereira Neto (2007) afirma que a compostagem pode ser desenvolvida em uma faixa de $\mathrm{pH}$ entre 4,5 e 9,5, sendo que os valores extremos são automaticamente regulados pelos microrganismos, por meio da degradação dos compostos, que produzem subprodutos ácidos ou básicos, conforme a necessidade do meio. No entanto, Primavesi (1981) afirma que as alterações do $\mathrm{pH}$ podem ativar ou quase inativar as enzimas presentes nos microrganismos.

Apesar da contradição apontada por RODRIGUES et al. (2006) e PEREIRA NETO (2007), quanto aos valores ótimos de $\mathrm{pH}$, sabe-se que não há problemas em se utilizar substratos que apresentem baixo $\mathrm{pH}$, já que durante a compostagem ocorrerá inúmeras reações químicas que irão regular esta acidez, gerando um produto final com $\mathrm{pH}$ entre 7,0 e 8,5.

Os valores de $\mathrm{pH}$ encontrados foram em média 7,76 para o tratamento com calcário, 6,8 para o tratamento com bactéria e para a testemunha 8,2 , sendo que somente o tratamento com bactéria não esteve na faixa descrita por RODRIGUES et al. (2006) e PEREIRA NETO (2007). Este fato pode ter ocorrido devido as características do $\mathrm{pH}$ da mistura reidratada das bactérias que foram utilizadas.

Segundo DIAS e VAZ (1996) em um estudo realizado empregando a técnica da compostagem, com o lixo orgânico, os valores de Fósforo apresentado nas análises do composto apresentaram-se como $30 \mathrm{mg} / \mathrm{L}$, o qual afirma ser um valor alto, com significância alta, quando os valores são maiores que 20. Analisando os valores apresentados pela Tabela 1, observa-se que em todos tratamentos, os resultados mostram-se com valores mais elevados, sendo o $\mathrm{T}_{2} \mathrm{o}$ valor mais alto encontrado, devido a presença do calcário que, segundo Silva (1998), sua utilização em compostos pode promover a elevação do $\mathrm{pH}$, aumentando a disponibilidade de alguns nutrientes como fósforo, nitrogênio, enxofre.

Para as análises de potássio a significância caracterizada como alta é de valores maiores que $90 \mathrm{mg} / \mathrm{L}$, estudos de compostagem com o lixo orgânico, trazem como valores de $225 \mathrm{mg} / \mathrm{L}$, sendo superior a significância, caracterizando-o como um valor alto de potássio. De acordo com a tabela 
$\mathrm{X}$, observa-se que os resultados das análises apresentaram-se de forma superior a significância, o que caracteriza ser um valor alto de potássio (DIAS e VAZ, 1996).

Em estudos referentes à compostagem com lixo orgânico foram encontrados valores aproximados de $225 \mathrm{mg} / \mathrm{L}$ de potássio, sendo que valores superiores a $90 \mathrm{mg} / \mathrm{L}$ já são considerados altos. De acordo com o s resultados obtidos para potássio, observa-se que os valores encontram-se acima do valor considerado (DIAS e VAZ, 1996).

\section{CONCLUSÕES}

O composto apresentou-se pronto após 11 semanas do início do experimento, ou seja, 77 dias, considerando-se um tempo apropriado para a prática da compostagem, visto que normalmente necessitam-se 90 dias para o mesmo ficar pronto.

As temperaturas apresentaram-se coerente com o esperado, obedecendo as fases da compostagem, com exceção a não ocorrência da primeira fase mesofílica, havendo um acompanhamento da temperatura da leira com a temperatura ambiente.

Os parâmetros odor, moscas, formigas, larvas na leira, chorume e larvas no chorume e umidade, apresentaram-se normais de acordo com o desenvolvimento da compostagem.

Nas análises dos compostos finais, o pH e o Nitrogênio apresentaram-se abaixo em comparação aos estudos encontrados na bibliografia, já o Fósforo e o Potássio apresentaram-se com valores elevados, comparando-os com outros estudos.

\section{AGRADECIMENTOS}

Os autores agradecem a colaboração da empresa onde foi realizada a pesquisa. Também a Universidade Federal de Santa Maria, campus de Frederico Westphalen, especialmente os professores, Prof. Dr. Alexandre Couto Rodrigues e Prof. Dr. Pedro Daniel da Cunha Kemerich.

\section{REFERÊNCIAS}

BRASIL, Portaria n 15/96, Ministério do Meio Ambiente, Diário Da República I série-B, nº19, p. 128-129, 1996.

BRASIL, Lei n. 12.305, de 2 de agosto de 2010, Política Nacional dos Resíduos Sólidos. Brasília, DF, 2 ago. 2010.

BUDZIAC, C. R., MAIA, C. M. B. F., MANGRICH, A. S., Transformações químicas da matéria orgânica durante a compostagem de resíduos da indústria madeireira, Quim. Nova, Vol. 27, Curitiba-PR, 2004. Disponível em:< http://www.scielo.br/pdf/\%0D/qn/v27n3/20165.pdf>. Acesso em: 21 ago. 2013.

CARMO, M. I. de S. Manual da Prática da Compostagem Doméstica. In Câmara Municipal de Passos Ferreira. Ambisousa. 2008. Disponível em:< http://www.uff.br/feuffrevistaquerubim/images/arquivos/publicacoes/zzquerubim_17_vol_2.pdf>. Acesso em: 22 ago. 2013.

DIAS, S. M. F., VAZ, L. M. S., Métodos de Monitoramento no processo aeróbico de compostagem-EEA/UEFS, Feira de Santana, n. 15, Bahia, 1996. Disponível em: <http://www2.uefs.br/ sitientibus/pdf/15/metodos_de_monitoramento.pdf>. Acesso em: 21 ago. 2013.

EMATER DF. Caderno de Inovações Tecnológicas, 2010. Disponível em:<http://www.emater. df.gov.br/sites/200/229/00002106.pdf>. Acesso em: 30 mai. 2012. 
EMBRAPA, Comparação de Composto Orgânico de Barcarena com Adubos Orgânicos Tradicionais Quanto às Propriedades Químicas, Belém-PA, 2002. Disponível em: < http://ainfo.cnptia. embrapa.br/digital/bitstream/item/27836/1/com.tec.70.pdf>. Acesso em: 27 jun. 2013.

FERNANDES, F., et al, Manual prático para a compostagem de Biossólidos, PROSAB, 1996. Disponível em: < http://www.finep.gov.br/prosab/livros/Livro\%20Compostagem.pdf>. Acesso em: 29 out. 2013.

KIEHL, E.J. Manual de compostagem: maturação e qualidade do composto. $4^{a}$ ed. E. J. Kiehl. Piracicaba. 173 p., 2004.

MORAES, L. de M., JUNIOR, D. R. de P., Gerenciamento de Resíduos de Abatedouro de Aves: Alternativas de Manejo de Tratamento, São Paulo, 2006. Disponível em: < http://www.bvsde. paho.org/bvsaidis/brasil20/iii-019.pdf>. Acesso em: 29 out. 2013.

PEREIRA, NETO J.T. 2007. Manual de compostagem: processo de baixo custo. UFV. Viçosa. 81 p.

PRIMAVESI, A. O manejo ecológico do solo: agricultura em regiões tropicais. Nobel. São Paulo. 535 p., 1981

SILVA, A. C, et al. Mineralização de nitrogênio e enxofre em solos brasileiros Sob influência da calagem e fósforo. 1998. Disponível em: <http://www.scielo.br/pdf/pab/v34n9/7620.pdf>.Acesso em: 29 out. 2013. 